\title{
Archetype, Psyche, World
}

\section{From Experience to Cosmopsychism}

\author{
Jon Mills | ORCID: 0000-0003-3673-0884 \\ Department of Psychosocial and Psychoanalytic Studies, University of Essex, \\ Colchester, UK and Gordon F. Derner School of Psychology, Adelphi \\ University, Garden City, NY, USA \\ psychologist@sympatico.ca
}

\begin{abstract}
In our dialogues over the nature of archetypes, essence, psyche, and world, I further respond to Erik Goodwyn's recent foray into establishing an ontological position that not only answers to the mind-body problem, but further locates the source of Psyche on a cosmic plane. His impressive attempt to launch a neo-Jungian metaphysics is based on the principle of cosmic panpsychism that bridges both the internal parameters of archetypal process and their emergence in consciousness and the external world conditioned by a psychic universe. Here I explore the ontology of experience, mind, matter, metaphysical realism, and critique Goodwyn's turn to Neoplatonism. The result is a potentially compatible theory of mind and reality that grounds archetypal theory in onto-phenomenology, metaphysics, and bioscience, hence facilitating new directions in analytical psychology.
\end{abstract}

\section{Keywords}

archetypes - psyche - psyworld - mind-body problem - panpsychism neoplatonism - collective unconscious - metaphysical realism - cosmopsychism Plotinus - transcendence - the one and the many - Whitehead

There is nothing more intellectually entertaining, and challenging, than the question of metaphysics, as it is about the ultimate ground, cause, scale, and possibility of Being, existence, and reality, not all of which are necessarily the same. In his most recent essay on the origins of Psyche, Professor Erik Good- 
wyn offers the most ingenious erudite attempt to lay out a grand metaphysics of mind most philosophers would blush at, let alone endeavor. Since two minds often achieve more than one, let us see how far we can go in our continued dialogue to address some of these vexing if not irresolvable conundrums that continue to beset our metaphysical postulates on archetypes, psyche, and world.

In our series of exchanges (Goodwyn, 2020a,b, 2O21; Mills, 2O2Oa,b), we have engaged in constructive discourse on the ground, scope, and demarcations of archetypes and the broader conceptual parameters of what constitutes the psyche. Although we have been preoccupied with the question and nature of archetypes, our discussion has now brought us to engage the larger metaphysical delimitations of psyche and worldhood. As such, our projects are concerned with fundamental ontology and specifically the question of origins, namely, that which precedes in time and importance. The query of whether there is a single origin is the subject matter of Goodwyn's (2021) latest essay. It is akin to asking what is the origin of the universe, which implicitly evokes a divinity principle, namely, the single cosmogonic act of all creation: in a word, God.

Goodwyn structures his investigation by asserting various ontological postulates, and then, following abductive inference, works them through to their logical conclusions. He starts with positing the existence of mind, which he equates with phenomenal experience on its most basal level, what he extends to consciousness and psyche, which I take to include all unconscious processes as well. From Descartes' cogito, Fichte's Absolute "I" (Ich) as pure self-posit, hence an act of self-assertion as the basis of psychic experience, to Hegel's "I am I" as the truth of self-certainty, any mental activity presupposes a thinker as an extant being: anyone who denies this (Dennett, 1988) is intellectually disingenuous or simply performing mental masturbation out of amusement. Goodwyn seems to privilege consciousness when he speaks of Mind and experience, when I take consciousness and unconsciousness to be equiprimordial yet erupting from an underworld wellspring of unconscious experience (see Mills, 2010), the locus of archetypes. What we appear to agree upon is that what is most basic is experience itself-as act, as process, as event. But rather than use "mind," "experience," "consciousness," and "psyche" interchangeably, as Goodwyn does, I would tend to make hierarchical distinctions with Mind and Psyche being more robust complex organizations, whereas consciousness being a set of ordinal phenomenal properties belonging to Psyche, while unconscious experience being the basic building blocks of all mental processes. 
We can even delineate experience into more descriptive functions and forms such as unconscious schemata, an archetype being one such schema. Yet unconscious experience as schematic events are also simultaneously in communion with its own being, one I have argued initially exists as pre-reflexive unconscious consciousness (Mills, 2002a), a rudimentary subjectivity as a given simple presence, a presencing that becomes more present in experiential complexity and manifestation. So even before experiential order can take shape unconsciously, let alone on macro-conscious levels of mind or psyche, experience and internal being are equivalent to existence itself, or more precisely, unconscious being-in-itself.

\section{The Ontological Principle}

Having prepared our discussion to include unconscious experience as a foundational starting point, Goodwyn centers on three conceptual divisions between self (ego), others (other minds), and world (matter) asking three further ontological questions, which I will reframe:

(1) What is the ground from which entities derive?

(2) What is their relation to one another?

(3) Are they metaphysically separate or distinct from one another?

The first is the question of original ground, and more precisely, what is the ground that does the grounding for experience to arise? We are in agreement that there must be a derivative principle from which all else emerges and originates; and following question two, their relationship to one another is primordial, as we could not experience nor have communion with anything in the natural world without relatedness, for all experience is positional (relational). However, the questions still remain: How, what kind, and in what way? Following Goodwyn's third query-Are entities ontologically separate?- - he is getting to the heart of the matter, pun intended. If mind or psyche, which for our purposes I will treat synonymously, is composed of experiential processes that coagulate and inhere in matter or our natural embodiment as psychic corporality, hence giving rise to consciousness, then the question becomes: Where does experience ultimately come from, or in other words, what is its cause?

From an onto-phenomenological framework, I have argued that unconscious experience is self-derived and self-constituted, arising from the rudimentary parameters of its initial natural interiority or psychic structure as an ontologically given process system. Goodwyn, on the other hand, asks an 
even more fundamental question: Where does Psyche ultimately come from? This leads him to posit a more primary or pre-original ground that he ultimately equates with the cosmos itself. But before we get there, and before my critique, it is important to show fidelity to Goodwyn's own method. He concludes that mind, objects, and matter indubitably exist, which we are in agreement, but he wants to explain how internal derivation (emergence) comes from the universe itself that is already derived and constituted, what we typically equate with reality, yet what he argues is simultaneously an enmattered psychic process system. If this is not a grand metaphysics, I don't know what would be.

Goodwyn is not satisfied with my conceptual limit (like Kant's Ding-an-sich, Fichte's Anstoss, or Husserl's epoché) or silence about where psyche comes from, as he sees this as tautological where "experiences come from themselves" despite avowing his proposition that mind exists. But we do agree that Psyche has ontological status and is real, so it becomes a matter of explaining how it is derived. "Where does all this come from?" he asks. Whereas I had confined my investigation to articulate how psyche and archetypes derive from unconscious process, Goodwyn asks us to venture into explaining how internal derivation is itself derived, hence either the psyche is (a) brute or given, or (b) "derives from something else." So ambitious in scope, I can hardly do justice to a thoughtful reply, as Goodwyn asks us to engage the ancient dilemma of first cause.

Following the ontological principle, we agree that something exists rather than nothing, albeit an ontology of nothingness may still exhibit metaphysical status as a realm of pure potentiality (the amorphous not-yet-realized), as absence, or more precisely, the presence of absence or lack, or as negation, for negation stands in dialectical relation to affirmation of being. Here being and nothing could merely be the inverse of the same thing. But the point I wish to make is that we are starting with something, as mind and the material world simply don't just pop-up ex nihilo, unless one wants to qualify that the manifestation of the manifold of objects in the world come from a prior ground that must be its own grounding - an ungrund or ground without a ground, or we keep appealing to prior conditions, which inevitable leads us to an infinite regress. We can simply start from the premise that psyche or cosmos merely is - as the brute given, and bracket how it got there, instead focusing on how it is organized or constituted, as the question, Where does it derive? forces us down a rabbit hole. The question is akin to asking, Where does matter, space, and time come from? Regardless, we will be begging the question of beginning as the origin of origins. As the issue of first principles cannot be eluded, Goodwyn ventures out of the brackets and invites us along on his journey of attempting to answer how Psyche originates, a most admirable enterprise. 
As a proponent of metaphysical realism, namely, that an extant world exists independently from our minds or subjectivities, I believe that objects in the external world do not require our consciousness of them in order to exist. It is unclear if Goodwyn subscribes to this view, but he probably would concur. This means that the mind-independent nature and character of the world is not contingent upon our capacity to cognize it, therefore it is non-epistemic despite any correlation between subjectivity and the objective world.

Because we both situate our arguments within a naturalized framework, mine from our onto-phenomenal embodied existence, and his from physics and bioscience without succumbing to reductive scientific naturalism, I believe it is fair to say that we both endorse a generic realism that has two basic components: (1) existence, and (2) independence, namely, the universe (populated with objects) exists independent of any observer or mind required to sustain it. In this sense, the truth of what is real is non-epistemic, for an alethic premise of truth does not depend upon our capacity to recognize it. Therefore, the ontological conditions that make something true, and hence constitute the world, need not be knowable because they are verification-transcendent. In other words, the universe would be there no matter what without needing to be constituted by a subject. Furthermore, the world would not disappear if all finite observers or perceivers were to cease to exist. Although my experiences depend upon my psychic reality, cosmos or world does not. Put another way, mind is a necessary condition of our experience of the world but not a sufficient condition to explain the existence of the world that is independent of our minds. Hence realism becomes an inference to the best explanation.

Having clarified my metaphysical position, we may further discern another ontological feature of mind and world: we are part of nature. We find ourselves as natural organic objects within a naturalized cosmos despite having our own sense of autonomous existence as sentient conscious beings (subjects) that are nevertheless dependent upon our natural embodiment from which we are entangled and emerge as differentiated self-conscious minds.

\section{On Other Minds}

Goodwyn concludes that mind or psyche exists by deducing his own mind, and then through abduction, extends this postulate to the existence of other minds. His task to prove the existence of other minds may be addressed both empirically and practically in order to subvert the accusation of solipsistic illusion, 
yet this so-called "classic problem" in reality is a philosophical trope. By virtue of the fact that we relate to external objects that present as subjects with subjectivities similar to our own is sufficient enough to prove an inner relation to a mediated object even if it is merely a representation. The notion of solipsism is untenable as we cannot help but relate to objects in the natural world in which we find ourselves situated as part of our thrownness.

We detect the agency of other minds via mentalization, as no computer, AI, or robot has ever passed the Turing test, at least not yet. Hence we recognize ourselves in another's mind as having a separate existence despite having the shared capacity of consciousness. Given our empirical encounters with others similar to our own agency, it further becomes reasonable to presume a principle of subjective universality based on our experiential intersubjective relations to like-minded others, which allows us to reasonably deduce that minds exist independent of one's own personal psyche. This conclusion is brought forth most convincingly by Hegel (1807) in the Phenomenology of Spirit in his chapter on Self-Consciousness where the truth of one's own selfcertainty is mediated by the recognition of "this other that presents itself to self-consciousness as an independent life, ... a certainty which has become explicit for self-consciousness itself in an objective manner" (PS §174, p. 109, italics in original). Hence "self-consciousness is Desire": we see the Other's desire that exists independently from us, and like us, also lacks and wants. "A selfconsciousness, in being an object, is just as much 'I' as 'object'. With this, we already have before us the Concept of Mind ... 'I' that is 'We' and 'We' that is 'I'" (PS § 177, p. 110). What Hegel so nicely captures is the psychological process of being attuned to other's minds, what in contemporary psychoanalytic parlance has become known as mentalization — sensing the intentionality and inner conscious states of others' cognitive processes, and more specifically, mentalized affectivity.

We form a hypothesis or theory of other's minds by virtue of the fact that we encounter intersubjective relations in spacetime. In fact, in order to perceive or know that we have mental processes is mediated and confirmed by our relational encounters with others, as we must have a sense of self-certainty in order to identify and acknowledge that others do as well, or we would not be able to recognize our sense of self in the other as a separate existence (Mills, 2002a). This further allows us to construct a mental representation of what other minds must be like through identification and internalization of shared similarities and differences, or we would never be able to construct a metarepresentational image of Otherness to begin with. First, we must respect the independence of the object (subject) as an autonomous being that has their own rich mental life experientially intuited and felt to be rationally deliber- 
ated by the mere fact that we sense they are reflecting on their own internal states of being. Since I am self-conscious of myself, I can readily see they are a self-conscious being as well engaging in cognitive, affective, and intentional (telic) reflective behaviors that are written on their embodied appearance (via body morphology, facial expressions, physical gestures, emotions, etc.). Here we cannot elude the logical conclusion that our objects of consciousness are themselves somehow minded and have self-consciousness in their own right as an objective feature of reality or we would not be able to identify them as such in our experiences of the world. A failure to mentalize would leave us in a hopelessly self-enclosed universe that has no capacity to appreciate the objectivity of external reality and hence aborted to a monadic void. That is not how we experience the world of objects and others, as we are constantly relating to objects and others in our own mind. In other words, no objects, no mind.

The qualia of our convictions fortify our beliefs in the universality of mind due to the cognitive, perceptual, and affective resonance states they produce upon us in our relational encounters with others based on such agency detection mediated through our own agentic relation to self-interiority. What this further means is that deducing other minds requires an act of self-conscious awareness that recognizes the basis of subjectivity in self and others, for the inability to separate out different minds from one's own like we do with objects in the external world would result in some form of unconscious autism.

\section{Minding Matter}

Professor Goodwyn is concerned with mereology and analyzes the part-towhole relations between isolated objects and parts of the body as bits of matter that, when form in an assemblage, we often attribute to mind as a whole. In other words, human minds possess psyche while partitioned off components, our organs, let's say, do not; yet when combined into higher-order organizations, they constellate as mind. We may now ask: How do parts become mind? If we cannot answer how the lower relation informs and becomes subsumed within a higher causal order, we have a problem with mereological reduction on the one hand, and how autonomous teleological organization on a macrosystem level is made possible on the other without reducing the whole to the sums of its parts. In order to address these concerns, Goodwyn alludes to two plausible possibilities: (1) all parts condition mind, and/or (2) parts are already proto-mental. This would mean they must either derive from something that is already psychic, or they become psychic when in synergy with an emergent complex process system. 
Goodwyn states that when following an onto-phenomenological approach " 'matter' is not given," when I have merely started from the empirical standpoint that psyche is embodied, therefore enmattered, hence is given just like our thrownness into worldhood. But Goodwyn does not want to beg the question of our enmattered psyche as a presupposition; he wants to explain how it is derived and how we get there, in other words, how we become psyche. His conclusion: "mind is a property that is possessed by the matter of which I am composed." Because isolated bits of matter do not exhibit the attributes of local mindedness, mindedness is informed by isolated parts only in conjunction to a mental system as a whole.

If mind is a "property" of "matter," does matter do the possessing or does psyche possess matter? If matter possesses psyche, then are we not confronted with a reductive mereological fallacy, not to mention displacing the question of agency? In other words, if mind is an emergent property of matter, how could it have any causal powers of its own, as it only would be a causally impotent epiphenomenon? But if matter is itself psychic, the conundrum is eluded. Yet how is this possible?

I have been operating within a bracketed set of ontological assumptions that start from the phenomenal dialectical unfolding of psychic processes within mind or psyche itself as mediated interiority, while Goodwyn is hazarding out into speculative metaphysical waters that contemplates the ultimate origins of Psyche itself. Whereas I posit that the basic units of experience are constituted as unconscious micro-process systems unfolding and reconstituting as higherorder process systems of consciousness, Goodwyn challenges us to provide an account of how experience begins and where it derives from. It is not merely a matter of showing how experiential complexity of enmattered (concrete) process systems - viz. archetypes or unconscious schemata (in his language, local mindedness) - become more complex and convoluted in their higher modes of psychic organization. In order for mind to retain causal efficacy, we must be able to show how micro-process mental systems share the same properties and essence of all matter. And since we have agency, our own agency must derive from a source, or essence, whether that be single, simple, or complex is another matter, where all entities must participate even if they possess no agency.

Before Goodwyn arrives at his destination of offering us a metaphysics of psyche, he dismantles the classic problem of materialism by arguing that physicalism cannot provide an adequate account of the mind-body problem (МВP) for 
it cannot explain how matter creates psyche let alone justify its causally reductive ontology. Here we are in agreement. We may further add the inconvenient irritant of a presupposed conceptual scheme that assumes mind and body are distinct: to accept matter vs. psyche is to enter into and confer a preestablished given binary, the very proposition of which is in question. Having already established that minds exist, Goodwyn then turns his attention to the question of panpsychism as an alternative to physicalism.

\section{Cosmopsychism: Plausibility and Skepticism}

Given that psyche exists, through inverse logic he challenges the materialist paradigm that takes as brute fact the physical existence of the universe in the absence of psyche, which he questions as the ground or cause of mind. Rather, he proceeds with the premise that psyche exists and tries to account for matter as either a creation or co-extension of psyche. He opines: "Because psyche (or proto-psyche) already exists everywhere to one degree or another, there is no need to give any explanation for how matter creates it. It is simply a property that exists in the universe that is possessed by some or all of said universe." But this commitment immediately lands him into hot water, which he acknowledges. If we can't convincingly establish that matter creates mind, then how about the other way around? But the same problem applies: you have to account for how psyche creates or coalesces matter if you posit it as the original cause. One option is to look at micro-panpsychic processes that then scale up to macro-organizations at the systemic level. Here panpsychism starts with the minute building blocks of the universe that are posited to be micropsychic and hence inform the bigger system, namely, one big macropsyche. But the same quandary reiterates itself that the physicalists face: in similar vein as the difficulty in explaining how micro-bits of matter create mind, how can tiny micropsyches come together to form one big universe animated as consciousness?

Goodwyn's solution: cosmopsychism - "the framework that proposes that the entire universe possesses consciousness" right down to atoms, electrons, and quarks. He argues that if we start with the whole as a system, we may then more readily infer how parts, subunits, or isolated bits of matter may be modifications or derivatives of the whole. Therefore, we are less likely to run into logical contradiction if the whole of the universe is posited as possessing psyche that then modifies itself and differentiates itself into parts or objects that would still retain the essence and properties of the whole in dispersed derivative forms. Mind may be explained as its own whole, which is a subsystem 
or altered form of the cosmos. A quantum particle is a further modification of universal mind on the most minute level of consciousness. Because every modification is the extension and stratification of Psyche's original essence, all objects and properties of the universe are strewn into a plurality of entities that retain their relation to the original unity. Goodwyn believes this eliminates the combination problem of explaining how both physicalist and micropsychic processes are said to emerge and create a macro-organization that scales up to create the whole as an aggregate mental apparatus. By starting with the whole - what we find ourselves emersed in as mind, society, and cosmos, or in my language, psyworld, Goodwyn asks us to adopt panpsychism as a viable solution to the МвP and the greater metaphysical constraints that condition the real through cosmogonic ontology.

Before I critique Goodwyn's position by adopting the onto-phenomenological method that starts with experience-near phenomena while extending such ordinal phenomenology beyond the human psyche to the cosmos as a whole, we must revisit how this challenges our views on metaphysical realism. Previously we argued that there is a universe that exists independent of our minds that cognize it, and there are no epistemic criteria required to maintain the extant world as its own autonomous ontological reality. But if the whole cosmos is psychic, metaphysical realism becomes compromised. If one adopts any version of panpsychism, this confounds the notion of realism as there would no longer be independent existence of anything from Mind for all of reality would be relegated to the psychic. This would by default make our realist claims some version of an anti-realist metaphysics or subsumed within some form of Idealism. How can the world exist independent of mind, hence evoking the ontological principle of metaphysical realism, when the universe to some degree possesses psychic processes? This means that there is nothing that exists independent of psyche, as all matter is infused with consciousness, and presumably must be so necessarily in order to sustain the real. Ergo there is nothing independent of mental processes that saturate the cosmos. Is there a way out of this pickle? Let us see how far we get before arriving at any definitive conclusions.

The merit of Goodwyn's theory is that it solves the logical problem of accounting for essence: nothing is completely estranged from the objects that saturate the universe because everything is a modification from an original source that is predicated on a Whole or philosophy of the Encompassing. Instead of starting with isolated bits of matter that form into particular arrangements and assemblances that become further organized into consciousness or psyche, hence the hard problem of neuroscience, Goodwyn starts with an organic whole and then works backwards toward understanding how parts or constituencies are distributed forms of essence into microprocesses that are 
extensions of a mature system. From a philosophy of organism where an ontophenomenology unfolds, in my thinking I begin with the micropsychic, what I call microagency, that then developmentally progresses into more robust forms of unconscious subjectivity that then breach into consciousness, thereby relying upon a dialectical logic of sublation where lower relations volute and are subsumed into higher ones as an organism acquires new forms of sophistication in its developmental helices. Here essence is basic to the most primitive as well as the more mature forms psyche assumes. Because I am working from the inside-out, I attempt to provide a framework where psyche emerges from the base material in which it finds its nascent self situated as embodied desire. In my system, psyche simply does not emerge ex nihilo, a point Goodwyn may have confounded, but is developmentally prepared through incremental forms of dialectical volution that organize into higher topographies of psychic evolution. The rudimentary given is already a microprocess that matures into an organic mental whole we call mind or psyche. Essence is diffused internally until it breaches externality, namely, the manifold of objects it encounters in consciousness.

Goodwyn's method is different: he jumps to the end and works his way back, where the whole explains how modified constituent parts may be understood to exist as emanations or dispersions from the mature organism in question. But here is the leap. Goodwyn does not confine this metaphysic to the human psyche or as a society of collective peoples, but rather extends to the whole cosmos itself as one enormous animating consciousness where everything else is derived.

Let us proceed with some paradoxical or aporic questions. How can the universe ponder itself? How can the cosmos think itself, let alone have selfconsciousness as an experientially aware entity that thinks? How can it think itself into being? Here we cannot escape the specter of supernaturalism or appeal to a divinity principle, as a psychic cosmos has generative powers to confer being onto other things through virtue of its capacity to dispense its essence into distributive forms and patterns throughout the universe including inanimate objects and animal bodies. And if plausible arguments can be given to defend these propositions, you still have to explain how Cosmopsyche came into existence as a cosmogonic act. And does this not beg the question of first cause? Here we fall into a black hole of infinite regress. So we must contend with the predicate that the universe has always existed in some form despite undergoing transmogrification as a processual system of the whole, or we must be prepared to tackle how a universe emerged or came into being as a psychic system. Regardless, we are back to the question of fundamental ontologyWhat is the origin of Being? 
How did consciousness magically get there in the cosmos to begin with as Universal Mind? It presupposes the very thing in need of explication as it presumes consciousness is everywhere, but it does not explain consciousness nor how it got there originally. To answer this, it bears repeating, we are either back to infinite regression, or we have to appeal to a creative function, divinity principle, or that the universe is eternal, infinite, and was never created-it was merely always there qua Being. So here Goodwyn is in the same quagmire I am when having to start with the brute given: while I appeal to embodied immediacy, he postulates a supraordinate source of all consciousness as the universe itself. I would argue I am on more stable ground by instituting the ontological bracket, but this does not answer to the greater metaphysical questions Goodwyn astutely raises.

\section{8}

\section{Transcendental Heavens}

Is Professor Goodwyn justified in extending his notion of psychic holism that is peculiar to human beings to the cosmos itself? Why should we assume Cosmopsyche exists as something that is brute structuring and suffusing the whole heavens when this may easily slide into theosophy where cosmos becomes the mind of God? Why not stay within the parameters of the human rather than superhuman, or conversely, simply make Psyche a generic abstraction or development of the universe? If we have the continued problem of not being able to adequately explain what consciousness is, which enjoys no uniform consensus, let alone how it arises, how are we any better off by importing consciousness to the physical universe where both psyche and matter are said to form an integrated unit? I cannot solve the matter of first cause, for, as previously stated, it either leads to infinite regression, circularity, begging the question, and/or the inevitable bog of antinomies that meet with no resolution, sublation, or discernible synthesis. But may I indulge the very questions that beset a grand metaphysics of inclusion required to justify a theory of holism cosmopsychism is said to afford?

How can distinct subjectivities belonging to distinct minds of individuals tally up to be combined in a single conscious Mind? Here the combination problem leads to incoherence because, by definition, if my mind derives from the One Big Mind holding everything together through interconnectedness, I should be able, in theory, to be in communion with every subject's consciousness as well as the Big Kahuna's. Since I am hardly aware of all aspects of my own mind, how could I be said to possess access to other's minds, let alone the properties, qualia, and viewpoints of all existing beings on the planet and 
throughout the galaxies, which is empirically unverifiable and logically impossible, therefore contradictory and incoherent? But Goodwyn offers us a potential explanation. Although the properties of micropsyches may be traced to the larger system and integrated within the whole, they lose their local integratedness when partitioned off into subsystems or units, and therefore this accounts for why parts of the whole system lose direct communication with one another, as they are alienated and discrete entities in their own right despite remaining in communion with the one large Unity as particulars within the universal that it emanates from. For Goodwyn, if I understand him correctly, psyche is neither derived from matter nor is matter derived from psyche, as they are both coextensive within a synchronized concomitant system whereby psyche inheres in matter and vice versa; yet this locally integrated psychic matter (and energy) ultimately derives from one entity, namely, the universe itself. Here Goodwyn succeeds in providing a reasonable argument that may account for how the binary categories of psyche and matter are fused in a concurrent co-system without privileging one as derivative of the other. Let's call this psymatter as shorthand for our psychic embodiment. But what about the cogency of prioritizing the premise and metaphysical status of the One from which all things derive?

By attributing an Über-Mind to the cosmos itself, Goodwyn is looking for the ultimate foundation in which all things arise and engage through a participatory metaphysics when I merely confine my investigation to the human psyche. The problems are enormous when attributing thought, consciousness, and psychological processes to an impersonal universe composed of a multiplicity of objects that are said to possess cognition that are differentiated yet further integrated or unified in the One. To reiterate, the most salient questions that draw into question the dubiousness of such claims come to mind. As previously stated, how can the universe think? How can it conceive of itself at all? How can it imagine? How can it feel? How can it be conscious of itself, hence self-aware? This would imply having self-consciousness and its own agency, especially if everything else that is extant is contingent and dependent upon the One's own being and actions that sustain all the bits and pieces of the cosmos through dispersion of its essence. And how could it scatter itself into other objects and subjects that populate the universe? What are the mechanics involved? Does it do so conceptually, through thought, or physically through the materialization of substance-energy-matter? Does it create an infinite sea of miniobjects that possess psymatter, or does it merely rearrange and allocate already existing psymatter in new and variegated forms? And what would be its motivations for doing so? In short, how could the universe possess soul let alone be the cause — the ultimate ground — of other souls? 
One attempt to address these aporias, albeit with their own set of problematics, is if we were to redefine what we typically mean by consciousness. Here Whitehead may prove to be instructive. Like Goodwyn, Whitehead $(1925,1929)$ proposes a philosophy of organism where reality is a holistic encompassing process system composed of basic drops of experience that saturate all objects, what he calls actual occasions or actual entities, that are related to everything in the universe through an interconnected ontic web of prehensions as concrescing occasions. Everything that exists or is actual has an elementary mind-like structure that scales up in aggregate form to the Whole as the nontemporal concrescence of all actual occasions that unifies and holds the cosmos together (Mills, 2002b). Although Whitehead goes to great lengths to distance himself from the language of consciousness and panpsychism, unconvincingly so, he also imports psychological properties and qualia to actual entities in the form of desire, feelings, and subjectivity, a deposit of the limits of human language in trying to articulate the internal dynamics of the manifold in relation to (and belonging to) a cosmogonic ontology. In this way, the universe is alive and teaming with energies but it is not entirely animate in the same manner as animal bodies, because different gradations of consciousness are posited to manifest differently, quantitatively and qualitatively, in different process systems and in different hierarchical societies (Mills, 2003). We know these basic vital processes exist thanks to modern physics and bioscience but are explained through different paradigms and semantic discourses. So, following Goodwyn, what is foundational is the essence of form as a process system however which way we wish to characterize it, the details of which are mute. But this brings us full circle back to the question of archetypes as a derivation of original form. Although Goodwyn looks to science and physics, even contemplating the universe being entangled at the quantum level, he would be among good company with Whitehead.

Professor Goodwyn (2021) summaries his conclusions and theses in the following manner:

In our modern terminology, the cosmos is composed of parts but the whole is always greater than the sum of its parts, so looking at the cosmos as anything other than a complete whole unto itself will always be ignoring the higher-order properties it possesses. Our holistic principle then can be seen as a restating of the Neoplatonic principle that all properties 'emanate' from the One like rays from the sun. The difference between the ancient and modern approach, however, is that we are being more careful about how we arrive at the holistic principle, beginning with the experientially near human psyche and seeing if we can logically deduce, 
through admittedly abductive reasoning, the originating principle, rather than simply stating it exists without justification and proceeding from there.

Goodwyn's logic is internally consistent and in many ways persuasive. But what happens if we don't buy into the premise that there is an ultimate "originating principle" and that there is simply a plurality of objects that constitute the cosmos that has always been infinite (Ananta) and uncaused, such as in the Vedic tradition or its permutation as the Ein Sof in Kabbalah? How can something be a "complete whole" when everything is in flux and is a process of becoming? What if the universe is nothing but multiplicity and particularity that are subsumed under a unity principle but are never unified, such as a container or cipher? What if holism is merely a semantic signifier for totality, hence a symbolic Absolute without the need to import entirety, finality, closure, it's completion and end? What if we do not concede that holism exists as an original metaphysical unity and instead are conditioned to seek unification and integration by virtue of reason in order to make sense of things rather than participating of or seeking a return to an originating symbiosis with a universal Source? What if the psychology of unitive thinking and the need for a "holistic principle" is based on the human desire for wholeness, peace, and merger with the notion of the ultimate, infinity, or God, rather than there truly being an actuality of Oneness?

\section{9}

\section{More Metaphysical Baggage}

Does the notion that everything derives from a holistic cosmic mind hold any water? Is this the ingenuity of creative imagination - merely a fantasy, the cunning of reason? It is hard to deny that if we accept these premises, our speculations on the mental may lead us down a Jungian path into the mystic. Goodwyn's turn to Neoplatonism comes with its own metaphysical baggage, as it presupposes and is committed to a first principle of (a) the One (hen) as a preordained Whole, which is ultimately conditioned and sustained by (b) a Divinity Principle or Godhead. The former proceeds from a philosophy of containment or encapsulation that spreads out through hierarchical derivation into processions or emanations of entities with their own series of metaphysical layers into a graded reality that come from the Source (first principle), which remains ineffable yet is connected and internal to the human soul through intellection and divinization (theurgy) practices (see Plotinus, Enneads; Proclus, Elements of Theology; Remes, 2008). This roughly corresponds to Goodwyn's scheme that 
makes the human mind derivative of the cosmos or universe. Despite my earlier reservations, this system of thought may be potentially compatible with metaphysical realism that espouses the belief in a mind independent reality that is simultaneously represented in mind by virtue of our shared essence, a conceptual move that was later adopted in Schelling's and Hegel's Naturphilosophie where mind as subject-object identity is seen as an organic development of nature. But there is a problem. How do we account for the one and the many?

Beginning with the premise from Parmenides that being itself is one, Plotinus initiates his treatise on the "philosophy of the One" (Enneads, vi.9[9].3.14) in the following fashion:

It is by the One that all beings are being, both those which are primarily being and those which are in any sense said to be amongst beings. For what could anything be if it were not one? For if things are deprived of the One which is predicated of them, they are not those things.

Enneads, vi.9[9].1.1-4

Here One is a unity of singularity that conditions all being. Singularity as unitarity is the essence of anything that exists, as the existence of all things is being. Yet the One is indivisible and is the original cause of being. There is no division, no separation, no difference within pure identity. It embraces a simplicity thesis of the rudimentary presence of identity where everything is collapsed into solitariness. The solitary is also further intimately connected to the notion of nothingness as "that which is not one (oude hen)" (Plato, Republic, 478b), which Plotinus espouses (Enneads, v.2[11].1.1). Only one exists or it is nothing (ouden).

Unity is essence and essence in-itself is unified, hence being the basis of all Being. Unity is foundational to everything, both ontologically and epistemologically. For the Neoplatonists, all that exists—-the many-is contingent upon the one as an unconditioned unity that conditions all unity (Enneads, v.3[49].15.12-14). And since all unity must be a united multiplicity within a unified whole, the whole itself is comprised of unities as its totality. Therefore, multiplicity is unified with the whole as "the unity of the totality of a multiplicity, just as much as the unity of each one of its individual components" (Halfwassen, 2014, p. 183). Without opposition, beyond all otherness, as the ground and source of all existence that transcends difference, the One is Absolute (apolyton) (Enneads, vi.8[39].20.6). Ultimately we are one, and the loneliest one at that, because nothing can exist other than a featureless sterile totality. If this is the case it is hardly worthy of worship when all singularity vanishes into singularity, like the manner in which Plotinus ends his ninth tractate of the final ennead, as "the passing of solitary to solitary." 
Goodwyn's adoption of Neoplatonic holism commits him to the conclusion that the One transcends yet conditions everything as the ordering principle to all Being and is the ultimate explanation of all reality. A standard criticism of Neoplatonic metaphysics is that because it posits the One as a transcendent unity, which exists before and beyond being itself, it is not able to maintain its relation to the derivation of all things as gradations of reality because it exceeds all things. The problem of the one and the many is that the One by definition is unchanging and lacks differentiation, multiplicity, and the attributes of being because it is conceived as a complete and holistic identity while at the same time is said to be the source of the multiplicity of beings. Put laconically, how can all things be from the One when it is estranged from the particular beings in which all things are said to derive and participate? The predicate as principle contradicts itself. Here we have the same problem with panentheism and natural theology that boasts the cosmological argument for the existence of God. The One becomes the Wizard of $\mathrm{Oz}$ behind the curtain that is supposed to be curtainless. In other words, there are no appearances in absolute singularity. All there is is one.

The transcendence of the One is an obstacle to a participatory metaphysics as it remains isolated from all beings in which it is said to commune. So either the multiplicity of beings must reside within the One or the One creates the universe of objects that reside outside of it's internal structure. The former violates the principle of simplicity of the whole where there is no multiplicity, differentiation, or attributes of objects and the latter violates the notion of monism as shared essence. If something is in the One, then it is not one as any distinctions shatter its primal unity. If something is one it is simply one, not many. And if there are derivations, gradations, and hierophanies of reality that are caused by the One, then how can these lesser realities be tantamount to the One? As Sara Ahbel-Rappe (2014) puts it, "how can absolute unity give rise to multiplicity in the first place?" (p. 168). The problem lies in its transcendence as crypto-theology.

It is beyond the scope of this project to offer a defense of Neoplatonism, for I simply wanted to highlight these ancient preoccupations and problematics. The question now becomes: How does all of this relate to analytical psychology? Applying Goodwyn's logical scheme that the human psyche derives from a cosmic Psyche, like Jung's notion of the Objective Psyche, the collective unconscious becomes the bedrock of the universe animated by the cosmos operating 
unconsciously. This is an important point to make, as we do not witness nor experience the cosmic psyche, that is, as having its own mind like we experience other people to have minds, yet through our internal relation to externality the world manifests in us. We are in psyche; we are psyworld. Here psyche is its own cosmos, a mirror of the whole. Our individual subjectivities are merely a particularity, an instance of one of the multiplicities of Neoplatonic metaphysics, one within one.

How are we connected to this collective unconscious? Because it manifests as the appearance of patterned form in all people regardless of time, place, culture, or peculiarity of our thrownness, namely, as archetypes. Cosmos awakens psyche, where we find ourselves as particularity within universality, as an encapsulated multiverse of the mind. Deep down we all likely experience some primal unity with the cosmos, no matter how faint, amorphous, or ill-defined, as it presents itself to us as primordial presence, totality, ineffability, wonder. In mereological terms, we are part of the whole.

Following a Jungian trajectory, the collective psyche releases its essence into archetypes that resurface in the minds of humans. They are eternal, as is the process of essence distribution. In Neoplatonic fashion, this objective psyche is the whole that establishes the array of psyches that constitute social collectives, what I have previously interpreted as emanations that "supervene" on our individualistic minds and subjective personalities (Mills, 2014). Archetypes are the primal forms instantiated within mind while the collective unconscious is the transcendental transpersonal field holding all psyches together through shared universality.

What may be more radical than attributing consciousness to the cosmos is the notion that the cosmos is unconscious. Given that modern physics tell us that approximately $95 \%$ of the universe is comprised of dark matter and dark energy clouded by the Higgs field that has never manifested, perhaps this is not such a farfetched concoction. If $95 \%$ of what is postulated to exist has never materialized nor been directly observed, it not only remains unconscious and unknown, it is believed to condition all of reality in every region of the universe. Yet it remains hidden. And anything hidden is the ultimate form of unconsciousness.

Perhaps the cosmic unconscious speaks to us indirectly, as something revealed yet concealed unconsciously, the intuition and emotional resonance of the need to merge with Origin as the desire for transcendence. To bathe in the primal source, our pure spirit and true home, eternal return; may we be at peace with God as the tensionless state of being one.

But aren't we now engaging in psychomythology as a transference to theory? In previous work (Mills, 2019) I have argued that the collective unconscious is 
merely a synecdoche for universality, or more specifically, a subjective universality that is part of all human minds as collective objectivity. There is no need to import a supernatural hypostasis as the cause and creator behind the scenes. Archetypes may be explained through naturalized psychology that both Professor Goodwyn and I have attempted to accomplish, each in our own ways. Do we need to take this next leap of faith to allot psyche to the universe to reasonably expatiate what we know about the human mind? Although I applaud his efforts to resolve the riddle of Being, I will leave it for others to decide such plausibility. In the end, we have both advanced an onto-phenomenology underlying various metaphysical assumptions about mind and cosmos that are integral to Jungian theory. I hope these new directions in analytical psychology lead to new research and developing insights that continue to shed light on the notions of archetype, psyche, and world.

\section{References}

Ahbel-Rappe, Sara (2014). Metaphysics: The Origin of Becoming and the Resolution of Ignorance. In The Routledge Handbook of Neoplatonism. P. Remes \& S. Slavea-Griffin (Eds.), pp. 166-181. London: Routledge.

Dennett, Daniel C. (1988). Quining Qualia. In Consciousness in Contemporary Science. A. Marcel \& E. Bisiach (Eds.). Oxford: Oxford University Press.

Goodwyn, Erik. (2021). The Origins of Psyche: From Experience to Ontology. International Journal of Jungian Studies, 13(2). Published online.

Goodwyn, Erik. (2020a). Archetypal Origins: Biology vs Culture is a False Dichotomy. International Journal of Jungian Studies, 13(2): 111-129.

Goodwyn, Erik. (2020b). Commentary on Mills' "The Essence of Archetypes." International Journal of Jungian Studies, 12(2): 207-216.

Halfwassen, Jens (2014). The Metaphysics of the One. In The Routledge Handbook of Neoplatonism. P. Remes \& S. Slavea-Griffin (Eds.), pp. 182-199. London: Routledge.

Hegel, G.W.F. (1807). Phenomenology of Spirit. A.V. Miller (Trans.), 1977. Oxford: Oxford University Press.

Mills, Jon (2020a). Archetypal Metaphysics and the Psyworld. International Journal of Jungian Studies. 13(2): 130-149. 10.1163/1940906o-bja10oo7

Mills, Jon (2020b). On the Origins of Archetypes. International Journal of Jungian Studies, 12(2): 201-206.

Mills, Jon (2019). The Myth of the Collective Unconscious. Journal of the History of the Behavioral Sciences, (55): 40-53.

Mills, Jon (2018). The Essence of Archetypes. International Journal of Jungian Studies, 10 (3): 199-220. 
Mills, Jon (2014). Underworlds: Philosophies of the Unconscious from Psychoanalysis to Metaphysics. London: Routledge.

Mills, Jon (2010). Origins: On the Genesis of Psychic Reality. Montreal: McGill-Queens University Press.

Mills, Jon (2003). Whitehead's Unconscious Ontology. Theory \& Psychology, 13(2): 209238.

Mills, Jon (2002a). The Unconscious Abyss: Hegel's Anticipation of Psychoanalysis. Albany, NY: State University of New York Press.

Mills, Jon (2002b). Whitehead Idealized: A Naturalized Process Metaphysics. Process Studies, 31(1): 32-48.

Plato. Republic. In The Collected Dialogues of Plato. E. Hamilton \& H. Cairns (Eds.), 1961, pp. 575-844. Princeton: Princeton University Press.

Plotinus (1966). Enneads. A.H. Armstrong (Trans. \& Comm.). Cambridge, MA: Harvard University Press.

Proclus (1963). Elements of Theology. E.R. Dodds (Trans. \& Comm.), 2004. Oxford: Clarendon Press.

Remes, Pauliina (2008). Neoplatonism. London: Routledge.

Whitehead, A.N. (1925). Science and the Modern World. New York: Macmillan/Free Press.

Whitehead, A.N. (1929). Process and Reality. Corrected Edition, D.R. Griffin \& D.W. Sherburne (Eds.), 1978. New York: Free Press. 